\title{
Catalytic behavior of nanostructured sulfated zirconia promoted by alumina: Butane isomerization
}

\author{
Jung-Hui Wang, Chung-Yuan Mou* \\ Department of Chemistry and Center of Condensed Matter Science, National Taiwan University, Taipei 106, Taiwan
}

Available online 26 November 2007

\begin{abstract}
Promotion of sulfated zirconia with alumina (ASZ) improves its catalytic activities in $n$-butane isomerization. The activity and stability of the sulfated zirconia catalysts are investigated in three different nanostructures: ASZ supported on MCM-41, ASZ nanoparticles, and Al-promoted mesoporous sulfated zirconia. The increase of activity was determined primarily by the amount of aluminum addition and the temperature of calcination. The remarkable activity and stability of the Al-promoted catalysts are due to an improved distribution of acid sites strength. The Al loadings in all three catalysts can be adjusted so that optimum catalytic activities for butane isomerization could be found. The increase of butane conversion can be as high as 6 times of that in un-promoted SZ catalysts. This is due to an enhanced amount of weak Brønsted acid sites with intermediate strength on the optimal catalysts. For nanoparticle form of sulfated zirconia, the activity is most steady which is related to the optimum distribution of weak Brønsted acid. On the other hand, too much strong Brønsted acid leads to rapid decay of activity because of coking and cracking. The overall reaction mechanism of the isomerization of $n$-butane over sulfated zirconia was discussed to understand the details in product distribution.
\end{abstract}

(C) 2007 Elsevier B.V. All rights reserved.

Keywords: Alumina; Sulfated zirconia; Mesoporous zirconia; MCM-41; Nanoparticle; Promoter; Butane; Isomerization

\section{Introduction}

Sulfated zirconia (SZ) has attracted much attention as a potential process catalyst for the isomerization of light $n$ alkanes at low temperature [1-4]. Because the equilibrium product distribution of the branched isomers is more favorable at low temperature, active sulfated zirconia would be useful in increasing the octane number of lower alkanes. Due to its simplicity in product distribution, butane isomerization has been frequently studied as a probe reaction for understanding the acidity of the heterogeneous catalysts [5-10].

Various promoters have been found to increase the catalytic activity of SZ in butane isomerization. Among these, $\mathrm{Fe}$ and $\mathrm{Mn}$ have been reported to dramatically increase the initial rate. Unfortunately, rapid deactivation of the catalyst is often observed [11,12]. The addition of p-block metal oxide, such as $\mathrm{Al}_{2} \mathrm{O}_{3}$ and $\mathrm{Ga}_{2} \mathrm{O}_{3}$, on the other hand give an increased steady activity. Gao and co-workers $[10,13]$ reported that the addition

\footnotetext{
* Corresponding author. Fax: +88622366 0954.

E-mail address: cymou@ntu.edu.tw (C.-Y. Mou).
}

of small amount of $\mathrm{Al}_{2} \mathrm{O}_{3}$ to the sulfated zirconia system leads to a catalyst with superior activity than the un-promoted sulfated zirconia and it is stable during $n$-butane isomerization at $250{ }^{\circ} \mathrm{C}$ in the presence of $\mathrm{H}_{2}$. The promoting and stabilizing effect of $\mathrm{Al}$ on sulfated zirconia (denoted as ASZ; A and SZ standing for alumina and sulfated zirconia) was subsequently confirmed by other groups $[14,15]$. The steadiness of activity is important for SZ catalyst to be industrially viable. The effect of alumina on SZ catalyst has been suggested to be due to increased sulfur retention and thus density of acid sites [15]. Later, however, it was reported by us that the redistribution of acid types is more closely correlated to catalytical activities [16].

It is known that the catalytic activities of SZ catalysts depend sensitively on their structure in the nanometer domain which in turn depends on the preparation and pre-treatment procedures $[17,18]$. The nanostructure of the catalyst will affect catalysis in two ways: (1) the transport of reactants and products, in particular, the extent of coking; (2) the dispersion of the sulfated zirconia which in turn will affect the acidity of the catalyst. In this paper, we will prepare ASZ catalysts of three different nanostructures to explore their catalytical behaviors; e.g. using 
MCM-41 as support [19-21]; ASZ as nanoparticles [22], and Al and $\mathrm{S}$ on ordered mesoporous zirconia $[23,24]$. Three methods were employed to synthesize various sulfated zirconia catalysts, including (i) direct impregnating zirconium sulfate on the mesoporous silica MCM-41(ASZ/MCM-41), (ii) sulfation of zirconia nanoparticles (ASZ-NP) and (iii) and templated synthesis for mesoporous zirconia oxide (AS/MP-ZrO $\mathrm{Z}_{2}$ ). The catalytic activities of these catalysts were examined using $n$ butane isomerization as the test reaction, and their effects in activity and stability enhancements were characterized using a variety of experimental methods. Related reaction mechanisms over the catalysts will then be proposed based on their product distribution, selectivity and acid features found for each catalyst.

The remarkable activity and stability of the Al-promoted catalysts are due to an enhanced amount of the weak Brønsted acid sites [16]. Given this advance, one would like to gain further understanding of the promotional and stabilizing effects of $\mathrm{Al}$ on active site of SZ. One needs to understand how this acid site distribution is related to the initial activity, its deactivation, and product distributions. With these detailed information, a mechanistic understanding of the butane isomerization may be closer.

\section{Experimental}

\subsection{Sample preparation}

Alumina-promoted sulfated zirconia supported on MCM41, designated as ASZ/MCM-41, was prepared by impregnation method described in our previous reports $[19,20]$. The catalyst contained $50 \mathrm{wt} \% \mathrm{Zr}$, calculated on weight basis of the calcined MCM-41, which is close to the dispersion threshold of zirconium sulfate on MCM-41. The alumina-promoted catalysts are labeled as $x$ A50SZ/MCM-41 with $x$ corresponding to the nominal alumina concentration in mol\% based on the amount of $\mathrm{ZrO}_{2}\left(\mathrm{Al}_{2} \mathrm{O}_{3} / \mathrm{Al}_{2} \mathrm{O}_{3}+\mathrm{ZrO}_{2}\right)$. Moreover, the unpromoted 50SZ/MCM-41 catalyst was obtained by the same process except substituting ammonium sulfate $\left(\mathrm{NH}_{4}\right)_{2} \mathrm{SO}_{4}$ for aluminum sulfate $\mathrm{Al}_{2}\left(\mathrm{SO}_{4}\right)_{3}$.

The sulfated zirconia nanoparticle catalysts were prepared as follows: $12.89 \mathrm{~g}$ zirconyl chloride was dissolved in $500 \mathrm{~mL}$ de-ionized water to obtain $0.4 \mathrm{M}$ solution and a solution of $25 \mathrm{~g}$ 28-30\% ammonia was added drop wise to the solution under vigorous stirring until the desired $\mathrm{pH}$ of 10.0 was attained. Then, the mixture was refluxed at $100{ }^{\circ} \mathrm{C}$ for $24 \mathrm{~h}$ and then via filtration and washed with excess water to eliminate chloride ions. Hydrous zirconia nanoparticle was impregnated with a $3 \mathrm{~g}$ aqueous solution containing the required amount of $\mathrm{Al}_{2}\left(\mathrm{SO}_{4}\right)_{3}$ by the incipient wetness method to obtain $x$ nominal mol\% $\mathrm{Al}_{2} \mathrm{O}_{3}$, calculated on the weight basis of $\mathrm{ZrO}_{2}$. The slurries were stirred for $1 \mathrm{~h}$ and dried in the oven at $100{ }^{\circ} \mathrm{C}$ to remove the excess water. Finally, the sample was calcined at $720{ }^{\circ} \mathrm{C}$ for $3 \mathrm{~h}$ in static air. Alternatively, hydrous zirconia was also impregnated with an adequate volume of ammonium sulfate to have an identical loading of $\mathrm{SO}_{4}{ }^{2-}$ ions based on the weight of $\mathrm{ZrO}_{2}$ in contrast with the catalysts promoted by aluminum. The sulfated and aluminum promoted catalysts are designated as
SZ-NP and $x$ ASZ-NP, respectively, with A and SZ standing for aluminum and sulfated zirconia, and NP for nanoparticle.

The alumina-promoted mesoporous zirconia catalysts are labeled as $x \mathrm{AS} / \mathrm{MP}-\mathrm{ZrO}_{2}$, with $x$ corresponding to the nominal alumina concentration in mol\% based on the weight of $\mathrm{ZrO}_{2}$ and prepared by impregnation method described in our previous report [16]. In addition, 9S/MP- $\mathrm{ZrO}_{2}$ catalyst was obtained by the same process except substituting ammonium sulfate $\left(\mathrm{NH}_{4}\right)_{2} \mathrm{SO}_{4}$ for aluminum sulfate $\mathrm{Al}_{2}\left(\mathrm{SO}_{4}\right)_{3}$ to obtain an identical quantity of $\mathrm{SO}_{4}{ }^{2-}$ ions on $9 \mathrm{~S} / \mathrm{MP}-\mathrm{ZrO}_{2}$ catalyst and it is used to compare the promotion of $\mathrm{Al}$ addition with $3 \mathrm{AS} / \mathrm{MP}$ $\mathrm{ZrO}_{2}$ catalyst.

\subsection{Characterizations}

Using $\mathrm{Cu} \mathrm{K} \alpha(\lambda=0.154 \mathrm{~nm})$ radiation in an operate mode of $40 \mathrm{kV}, 30 \mathrm{~mA}$, the powder X-ray diffraction patterns (XRD) were recorded on a Scintag X1 diffractometer. The surface area and $\mathrm{N}_{2}$ adsorption-desorption isotherms were determined at $-196{ }^{\circ} \mathrm{C}$ with a Mircomeritics ASAP 2010 instrument. The specific surface areas were calculated according to the BET method and the pore size distribution curves were obtained from the BJH (Barrett-Joyner-Halenda) method.

Transmission electron microscopy (TEM) micrographs were taken with a Hitachi H-7100 instrument operating at $75 \sim 100 \mathrm{kV}$ or a Philips CM200 at $200 \mathrm{kV}$. X-ray photoelectron spectroscopic analyses (XPS) were performed using a Thermo VG Scientific, ESCALAB 250 fitted with a monochromatic Al $\mathrm{K} \alpha$ radiation $(1486.8 \mathrm{eV}) \mathrm{X}$-ray source, under a residual pressure of $\sim 1 \times 10^{-9}$ Torr. The spectra were recorded for the 385$420 \mathrm{eV}$ region to determine the $\mathrm{N} 1 \mathrm{~s}$ and then de-convoluted into sub-bands (sum-function of Gaussian and Lorentzian, 90\% Gaussian, $10 \%$ Lorentzian) with software, XPSPEAK, from RCSMS lab using an integrated background subtraction.

\subsection{Catalytic reaction}

The butane isomerization reaction was carried out in a fixedbed continuous flow system under atmospheric pressure. Approximately $1.0 \mathrm{~g}$ of 5A50SZ/MCM-41 catalyst (20/60 mesh) was loaded into the reactor and pre-treated in flowing air for $3 \mathrm{~h}$ at $450{ }^{\circ} \mathrm{C}$. After decreasing and stabilizing the temperature to $250{ }^{\circ} \mathrm{C}$, the reactor was flushed with nitrogen for $30 \mathrm{~min}$ and finally fed with a mixture $1 / 10(\mathrm{v} / \mathrm{v}) n$-butane $/ \mathrm{H}_{2}$ (WHSV $=0.31 \mathrm{~g}_{\text {butane }} \mathrm{h}^{-1} / \mathrm{g}_{\text {cat. }}$ ). The flow rate was controlled using a Brooks mass flow controller. The products were monitored and analyzed with a Shimadzu 14B gas chromatograph with a $60 \mathrm{~m}$ DB-1 column and FID detector. Besides, in the system of ASZ-NP and AS/MP- $\mathrm{ZrO}_{2}$ catalysts, the sample weight is adjusted to $0.5 \mathrm{~g}$ with a WHSV value of $0.62 \mathrm{~h}^{-1}$.

\section{Results}

\subsection{Characterization}

All three nanostructured catalysts display tetragonal crystal phases after proper calcination. The XRD patterns 


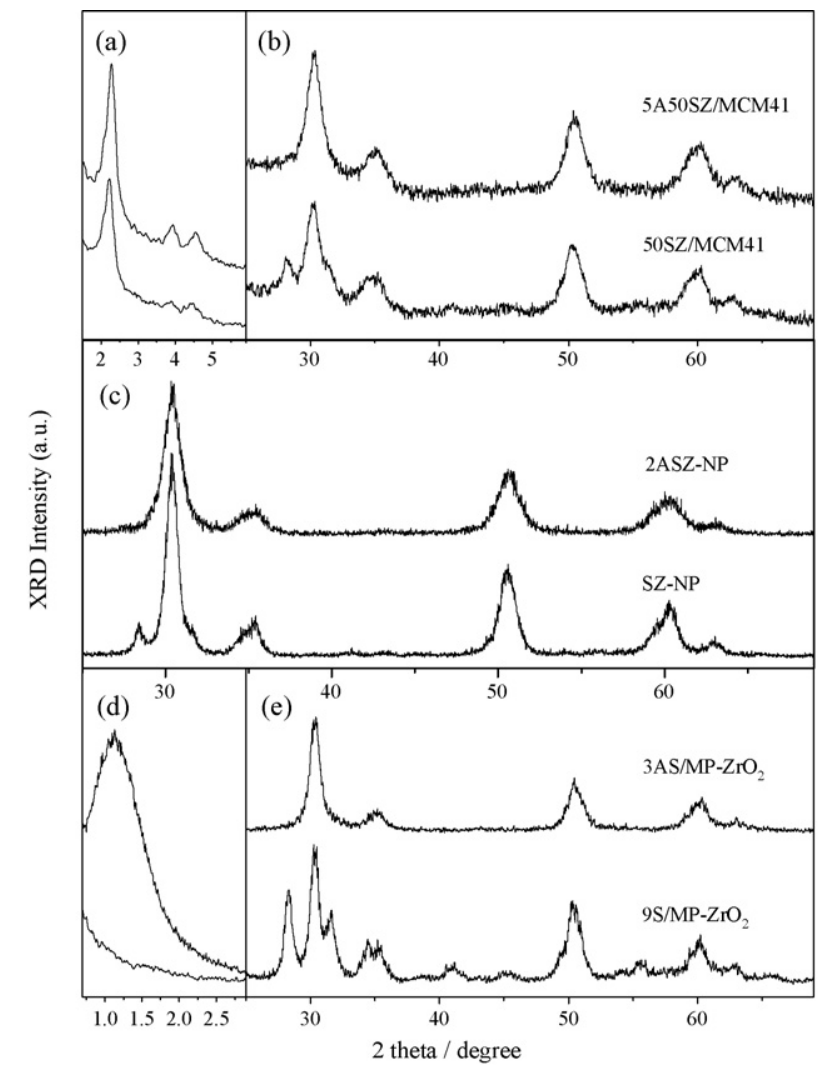

Fig. 1. XRD patterns of various catalysts calcined over $650{ }^{\circ} \mathrm{C}$ with an optima alumina content and without alumina loading.

of various catalysts, which exhibit best catalytic performance, before and after alumina are shown in Fig. 1. From top to bottom, the curves belong to sulfated zirconia (a,b) supported on MCM-41, (c) in nanoparticle form (ASZ-NP), and (d, e) mesostructure SZA(AS/MP- $\left.-\mathrm{ZO}_{2}\right)$. These patterns were recorded for investigating the influence of alumina loading on the catalysts. In the high angle region, the diffraction peaks due to zirconia crystallites were observed and the size of the crystal domain could be calculated by Scherrer equation. Firstly, all catalysts without alumina loading display mixed crystalline of tetragonal and monocline phases. Gao and coworker $[5,10,25]$ observed the stabilization of tetragonal phase of zirconia upon the addition of alumina. They proposed the alumina-enhanced catalytic performance of sulfated zirconia was resulted from the retardation of phase transformation from a metastable tetragonal phase to the thermodynamically favored monoclinic phase. Even when the calcination temperature is over $650{ }^{\circ} \mathrm{C}$, above which monoclinic phase is more stable than tetragonal phase, the catalytically active tetragonal phase was still preserved on the catalysts.

Besides, the sulfur contents of catalysts depend on the synthetic conditions. We added aluminum sulfate as the precursor of alumina, and used ammonia sulfate in place of aluminum sulfate in the same amount of sulfur species to synthesize the non-Al catalysts. The higher sulfur contents of alumina-loaded catalysts imply that aluminum improved the

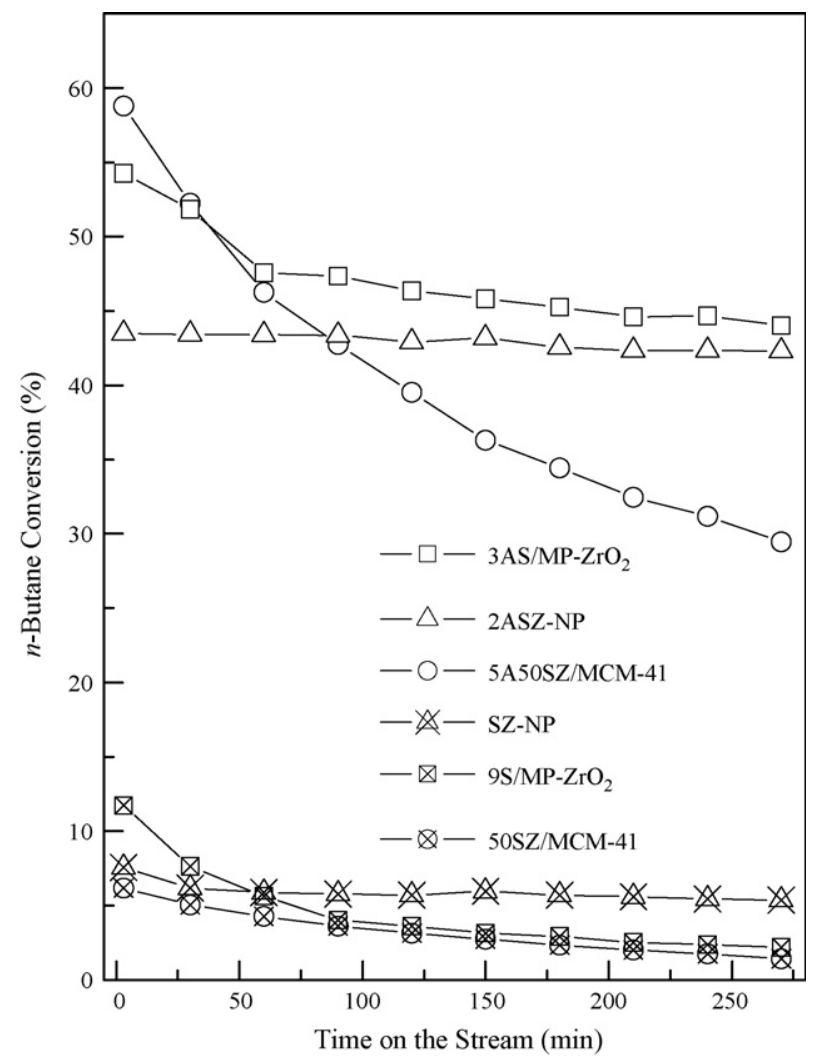

Fig. 2. Comparing the catalytic conversion over different catalysts with presence and absence alumina (data for $3 \mathrm{AS} / \mathrm{MP}-\mathrm{ZrO}_{2}$ taken from ref[16]).

retention of sulfate. As expected, the catalysts with higher sulfur content exhibit better catalytic performances.

\subsection{Catalytic activity}

Fig. 2 shows the variation of the conversion versus time on stream for different catalysts in the absence and the presence of alumina loadings. It is observed that the activity of all catalysts without alumina is much lower and the addition of an optima amount of alumina greatly improves the catalytic activity.

One may notice that although the initial conversions are above $50 \%$ for the two mesoporous catalysts, they decayed in $2 \mathrm{~h}$. On the other hand, the nanoparticle catalyst ASZ-NP displays a more stable activity. Further comparing the two mesoporous catalysts, mesoporous zirconia supported SZA $\left(\mathrm{AS} / \mathrm{MP}-\mathrm{ZrO}_{2}\right)$ gives more stable catalytic activity than 5A50SZ/MCM-41 although the later gave higher initial activity. The worm-like pores of AS/MP$\mathrm{ZrO}_{2}$ probably provide better transport due to more interconnections between the nanochannels. Thus the easier escape of product leads to less coking in AS/MP- $\mathrm{ZrO}_{2}$.

Recently, several works reporting high surface area mesoporous sulfated zirconia have appeared [26-28]. But these materials show relatively low activity for $n$-butane isomerization compared with conventional sulfated zirconia catalysts. The low catalytic activity over these catalysts is probably due to the absence of tetragonal crystalline phase, which is necessary for the formation of sulfated zirconia catalysts of good activity. 


\subsection{Acidity - the effect of alumina}

The nature of the acidic sites may be determined by XPS measurements of $\mathrm{N} 1 \mathrm{~s}$ of the adsorbed pyridine. The XPS peak position and intensity of the $\mathrm{N} 1 \mathrm{~s}$ peak of adsorbed pyridine could be used to investigate the type and strength of acid sites displayed on catalysts. It was shown that the $\mathrm{N} 1 \mathrm{~s}$ peak could be de-convoluted into three components [16]. Three kinds of acid sites were identified on the catalyst: a Lewis site, a weak Brønsted site and a strong Brønsted site. In this paper, the peak at $399.8 \mathrm{eV}$ is assigned to pyridine's nitrogen adsorbed on a Lewis acid site, and the peaks at 401.5 and $403.0 \mathrm{eV}$ are assigned to nitrogen connected to a weak and a strong Brønsted acid sites, respectively [29]. Fig. 3 shows the results of fittings which gives the relative acid sites fractions in the three catalysts as a function of different alumina loadings. The relative amount of the various acid sites changed significantly upon the $\mathrm{Al}$ addition. In these curves, similar trends were observed: the fraction of Lewis acids is decreasing with increasing alumina loading and the fraction of strong Brønsted acid (SB) is increasing with alumina. Further analyzing the components of Brønsted acids, it is found that the trend of weak Brønsted sites (WB) exhibit a volcano shape versus alumina loading unlike the curve for the strong Brønsted sites. Previously, we have shown that the total number of acid sites remain roughly unchanged with $\mathrm{Al}$ loadings [16]. It seems the number of WB sites grow at the expense of Lewis acid sites at Al loadings less than the maxima of the volcano. On the other hand, WB sites decrease as $\mathrm{SB}$ increases at $\mathrm{Al}$ loadings higher than the maximum of the volcano curve. These observations are in general agreements with our previous analysis [16].

Fig. 4 describes the variation in conversion (dark mark) and selectivity (hollow mark) of various catalysts with different alumina loadings at the initial $3 \mathrm{~min}$ (dash line) and steady state (solid line). Again, each conversion curve shows a clear volcano curve at an optimum Al loading. In all the catalysts giving the highest activity, the content of the weak Brønsted acid sites become the highest. On the other hand, the content of the strong Brønsted acid sites seems to increase roughly with $\mathrm{Al}$ content. The 5AS/MP- $\mathrm{ZrO}_{2}$ sample, though giving the highest amount of strong acid site, shows relatively low catalytic activity at longer reaction time.

Fig. 5 shows the time-dependence of the conversion and selectivity of $n$-butane isomerization on different catalysts and more details about products distribution are summarized in Table 2. The circles in Fig. 5 represent $3 \mathrm{AS} / \mathrm{MP}-\mathrm{ZrO}_{2}$, an optimal catalyst both in $\mathrm{Al}$ loading or calcination temperature. The conversion decayed from 55\% to $47 \%$ in the initial $60 \mathrm{~min}$ while corresponding selectivity varied from $86 \%$ to $91 \%$. The improvement of initial conversion over un-promoted 9S/MP$\mathrm{ZrO}_{2}$ is about five-fold. Table 2 gives detailed information about conversions, selectivities, and yields of alkane products. Un-sulfated $\mathrm{MP}-\mathrm{ZrO}_{2}$ shows very low activity but with higher selectivity for isobutane. The weaker acidity in $\mathrm{MP}^{-} \mathrm{ZrO}_{2}$ does not give much cracking. It is interesting to observe the distributions of minor alkanes in the product. Initially, the ratio of $\mathrm{C}_{3} / \mathrm{C}_{5}$ is very large. Propane is presented much more than
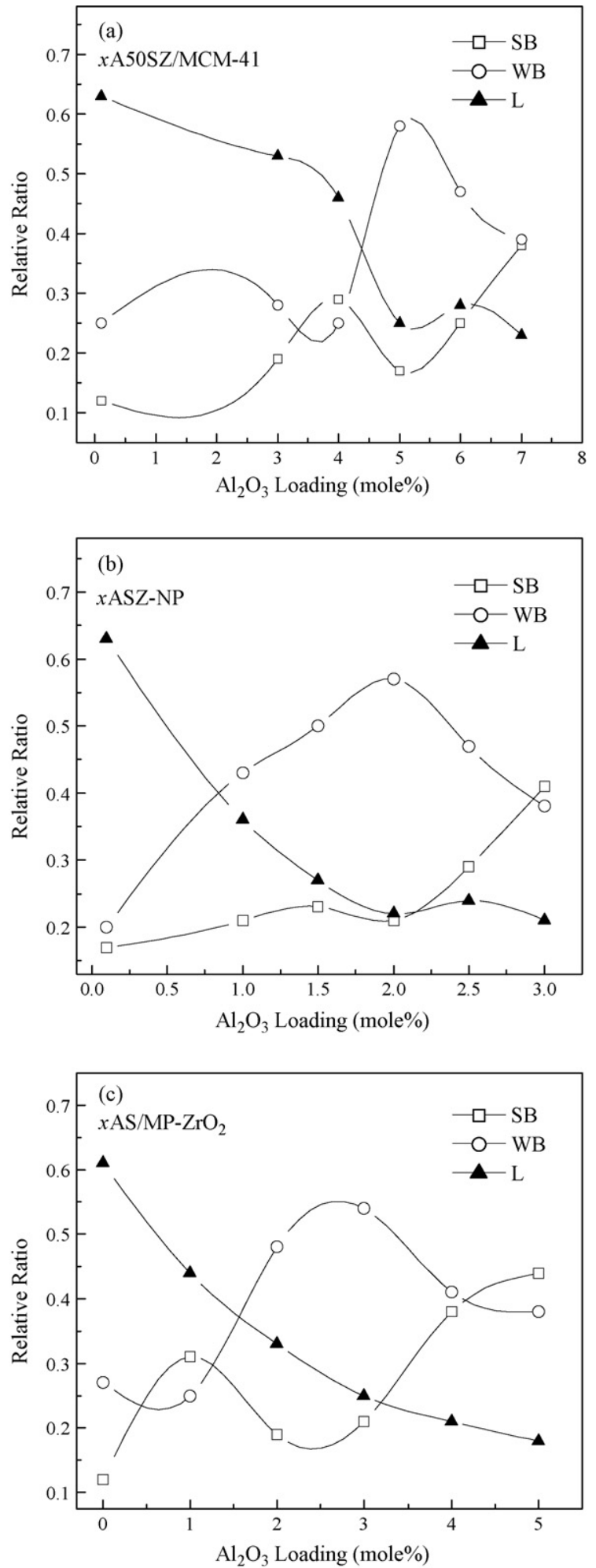

Fig. 3. Relative ratio of surface acid sites, as determined by XPS spectra of pyridine adsorbed catalysts, with variations of alumina contents.

pentane in product. However, after a rapid decay of activity in about one hour, the ratio of $\mathrm{C}_{3} / \mathrm{C}_{5}$ becomes close to one. This behavior also holds for the ASZ/MCM-41 sample. However, for the nanoparticle (NP) samples the catalytic behavior is somewhat different and interesting. Table 3 lists the conversion and selectivities of several NP catalysts. These catalysts, either 

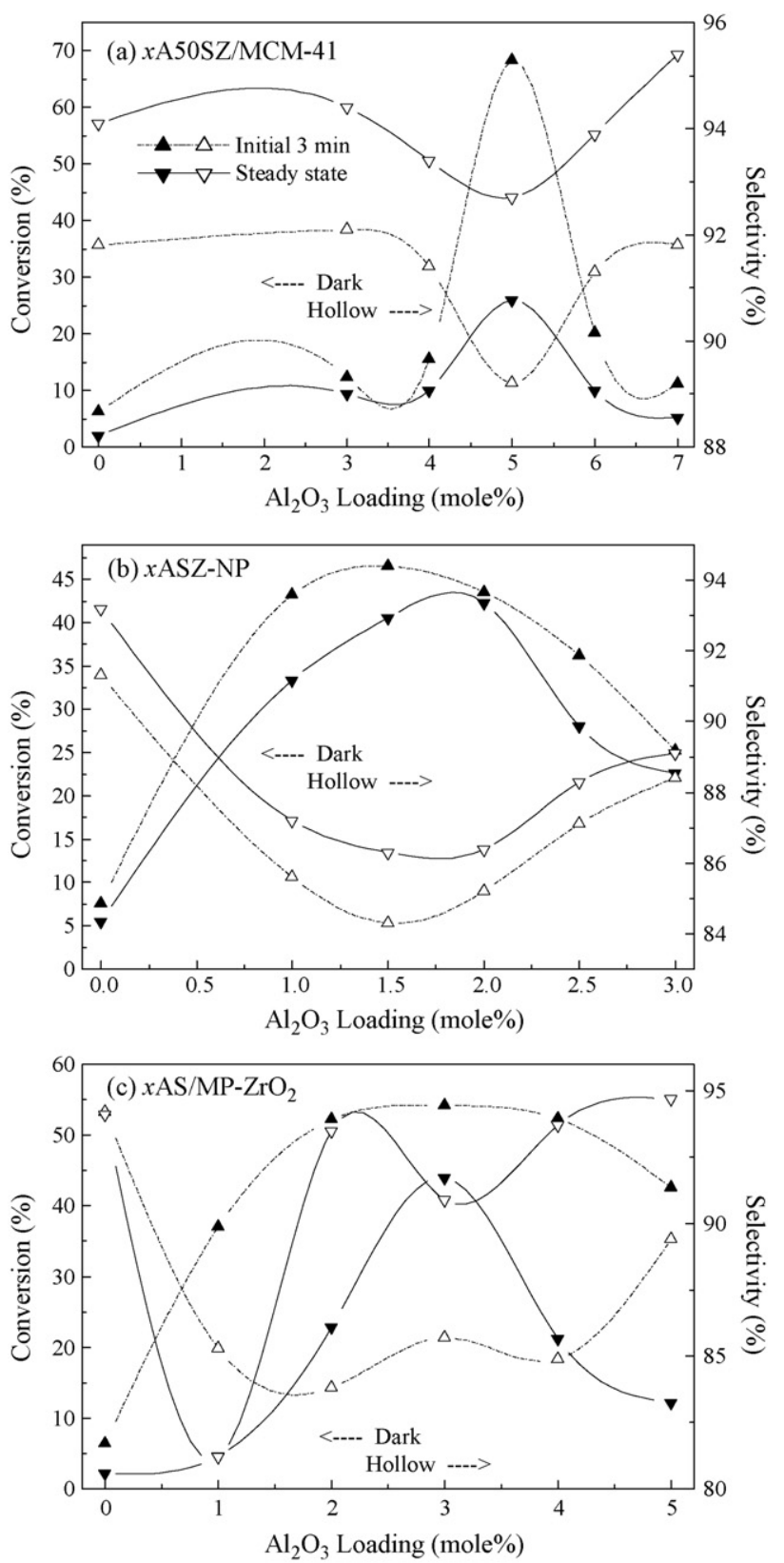

Fig. 4. The catalytic conversion and selectivity, at initial time and steady state, versus various alumina loadings over catalysts. In the case of 5A50SZ/MCM41, we take the last data point at $275 \mathrm{~min}$ as the steady state data.

un-promoted (SZ-NP) or promoted at various levels (1 ASZ-NP, 1.5ASZ-NP and 2ASZ-NP), give more steady conversion and selectivity over time. The ratio of the main cracking products $\mathrm{C}_{3} / \mathrm{C}_{5}$ are close to one from the beginning of time-on-stream and maintain such at longer time. As shown in Fig. 2, the 2ASZNP catalyst gives a very steady catalytic performance. Its implication in catalytic mechanism will be discussed in the next section.

\subsection{Acidity-temperature effect}

The surface area, pore volume, pore diameter, and sulfur content of 5A50SZ/MCM-41 catalysts calcined at different temperature were also investigated. These samples generally had surface area around $500 \mathrm{~m}^{2} / \mathrm{g}$, pore volume about $0.40 \mathrm{~cm}^{3} /$ $\mathrm{g}$, and pore diameter at $2.3 \mathrm{~nm}$. During calcination, thermal decomposition of zirconium sulfate yielded sulfur which is retained on the surface to form the active center of sulfated zirconia. The sulfur content from $1.63 \%$ to $0.93 \%$ is related to the calcination temperature and is inversely proportional to the temperature. The activity of catalysts increased with the final calcination temperature till $720{ }^{\circ} \mathrm{C}$ then it decreased above this optimal temperature (figure not shown here).

\subsection{The effect of nanostructures in catalyst}

Fig. 6 shows the HRTEM graphs of (a) 5A50SZ/MCM-41, (b) $2 \mathrm{ASZ}-\mathrm{NP}$, and (c) $3 \mathrm{AS} / \mathrm{MP}-\mathrm{ZrO}_{2}$ catalysts after calcination. In Fig. 6(a), well-ordered channels with continuous walls are clearly observed and scattered with sulfated zirconia nanoparticles. It shows the zirconium oxide not only exists in the channel to spread a thin film around the wall of MCM-41 but also outside of the channel. It is worth mentioning that the sulfated zirconia particles formed are in nanoscale. Based on the nature of metal oxides, aggregation of these particles prevails under impregnation process. Therefore, a reasonable supposition is these channels provide a steric restriction on formation of zirconium oxides nanoparticles instead of bulk materials.

Well-dispersed nanoparticles with spherical shape were observed from the graph of Fig. 6(b). The narrow size distribution may be due to the reflux process following precipitation making hydroxyl ions uniformly distributed throughout the whole sample and forming the hydrous oxides homogeneously [30].

The TEM image of $3 \mathrm{AS} / \mathrm{MP}-\mathrm{ZrO}_{2}$ catalyst exhibits wormlike mesoporous. This confirms that the single diffraction peak in the small angle region of XRD spectrum is indicative of a disordered mesostructure.

It is generally considered that the initial decay in activity results from the catalyst coking [31] and obstruction of active acid sites. To confirm this view the regeneration of 3AS/MP$\mathrm{ZrO}_{2}$ is illustrated in Fig. 7. It shows that the catalyst can recover its activity completely after being treated at $450{ }^{\circ} \mathrm{C}$ in air for $6 \mathrm{~h}$. This result may provide evidence that the deactivation of the catalyst in the initial period of the $n$-butane isomerization mainly result from the coking deposited on the catalyst surface. Besides, the excellent activity without decay of 2ASZ-NP catalyst (Fig. 2) suggests the nature of porous structure (pore connectivity) seems to influence product distribution and thus degree of coking.

\section{Discussion}

In this work, isomerization of $n$-butane was performed over solid acids of Al-promoted sulfated zirconia. We have investigated the catalytic activities in three catalysts of $\mathrm{Al}$ promoted sulfated zirconia with different pore structures. Now, we would like to compare their catalytic behaviors. 


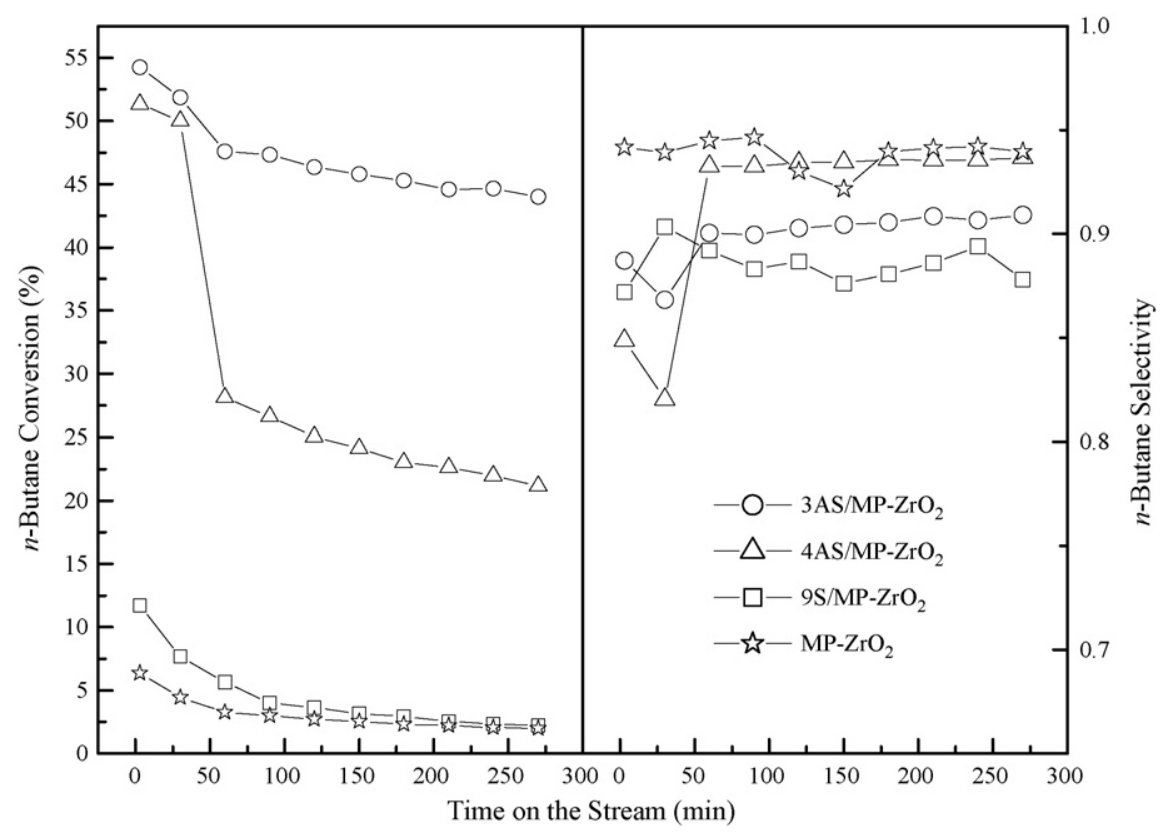

Fig. 5. The catalytic conversion and selectivity of $3 \mathrm{AS} / \mathrm{MP}-\mathrm{ZrO}_{2}, 4 \mathrm{AS} / \mathrm{MP}-\mathrm{ZrO}_{2}, 9 \mathrm{~S} / \mathrm{MP}-\mathrm{ZrO}_{2}$, and $\mathrm{MP}-\mathrm{ZrO}_{2}$ catalysts.

First, we would like to comment on the crystalline phases of zirconia in the catalysts. It is known that tetragonal phase is catalytically the more active phase. The addition of alumina certainly helps stabilizing the tetragonal phase against monoclinic phase in the nanocatalysts. Comparing these two crystalline phase in the lattice units, there is one oxygen vacancy in the tetragonal phase that gives the structural instability and further rearranges surrounding atoms to form monoclinic phase. Therefore, it is reasonable to assume the added alumina species provide oxygen atoms to occupy the surface vacancy and stabilize the tetragonal phase.

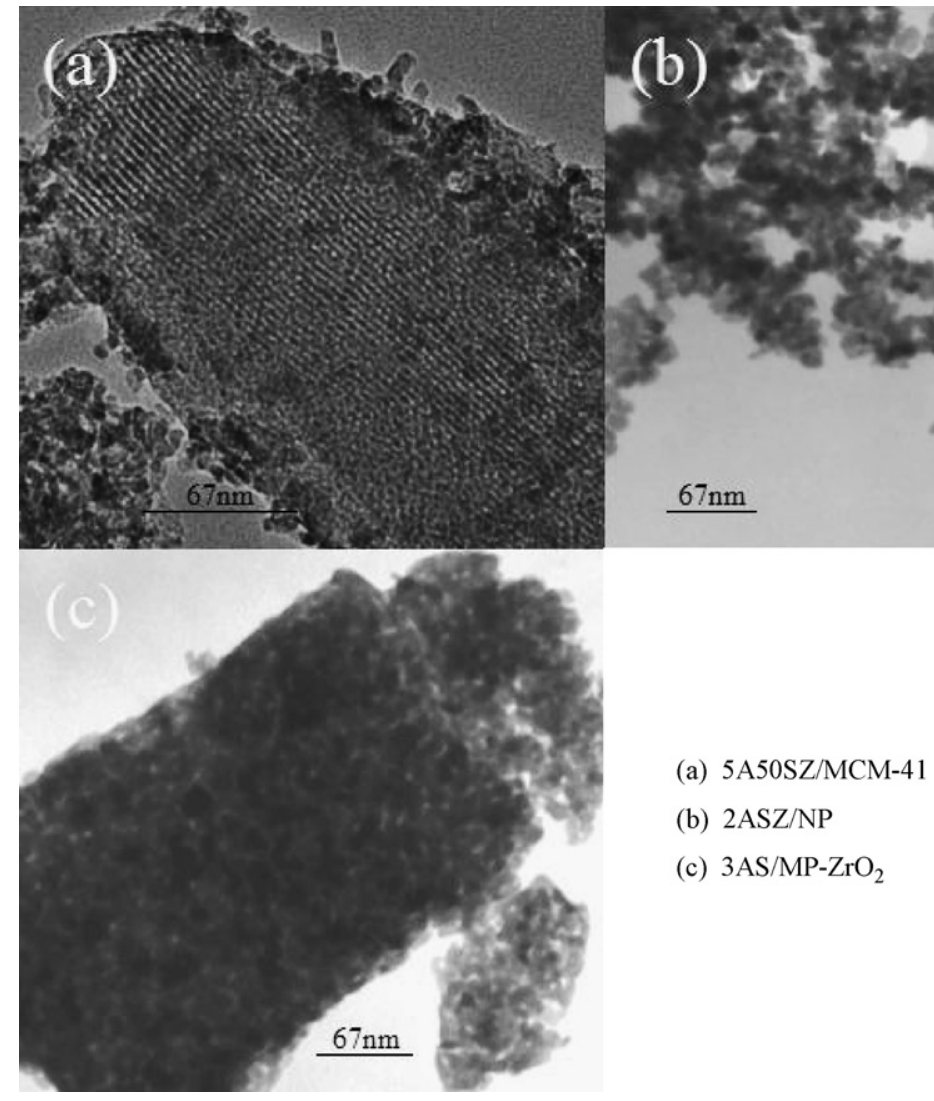

Fig. 6. The TEM images of different catalysts (a) 5A50SZ/MCM-41, (b) 2AS-NP, (c) 3AS/MP-ZrO 2 . (Part c reprinted with permission from Elsevier.) 


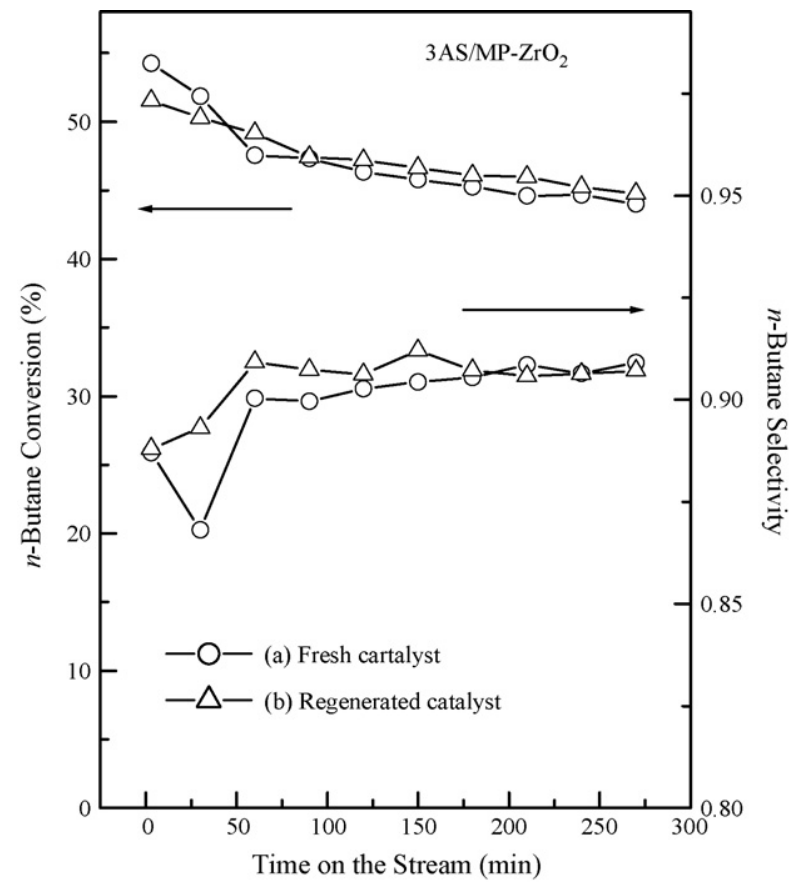

Fig. 7. Regeneration of $3 \mathrm{AS} / \mathrm{MP}-\mathrm{ZrO}_{2}$ catalyst. (a) Fresh catalyst and (b) catalyst regenerated at $450{ }^{\circ} \mathrm{C}$ for $6 \mathrm{~h}$.

Second, in the porous catalyst systems, the samples with alumina display more ordered porous feature in the case of mesoporous zirconia. These alumina species had a stabilizing effect on the mesoporous structure. Third, from the calculated particle sizes (by Scherrer equation), the alumina addition gives smaller zirconia domain size and possesses larger surface area. In Table 1, the surface area increases with the loading of alumina except for the catalysts supported on MCM-41. For the MCM-41 case, the surface area is determined by the mesoporous silica and higher amount of loadings would reduce surface area. But in the nanoparticle and mesoporous zirconia systems, the loading of alumina interrupted the linkage of zirconia and affected the formation of smaller domains. For example, the particle size of NP catalysts reduced from 9.91 to $5.93 \mathrm{~nm}$ as a result of the addition of alumina.

In Fig. 2, we compare the activities of the three different kinds of nanostructures of ASZ catalysts, each at optimized level of $\mathrm{Al}$ loadings for activities (see Fig. 4). The two catalysts 3AS/MP$\mathrm{ZrO}_{2}$ and 5A50SZ/MCM-41 have been previously investigated by us $[16,32]$. In this paper, the conversion behaviors of the two catalysts are quite similar to those reported before. The initial activities of the three catalysts, are in the order of 5A50SZ/ MCM-41 $>3 \mathrm{AS} / \mathrm{MP}-\mathrm{ZrO}_{2}>2 \mathrm{ASZ}-\mathrm{NP}$. However, the stability of the three catalysts are quite different; in the order of 2ASZ$\mathrm{NP}>3 \mathrm{AS} / \mathrm{MP}-\mathrm{ZrO}_{2}>5 \mathrm{~A} 50 \mathrm{SZ} / \mathrm{MCM}-41$. It seems the smaller the pore size of the catalyst is, the less stable of the activity will be. Part of the reasons may be that alkanes would adsorb and desorb more frequently on narrower pore and spend more time on its acidic surface. We also note that the pore system in 5A50SZ/ MCM-41 is more obstructed by SZ particles than in 3AS/MP$\mathrm{ZrO}_{2}$, as shown in their TEM micrographs (Fig. 6). This would in turn lead to more coking and de-stabilize the catalytic activity. It seems mesoporous zirconia catalytic system may worth more investigations as a catalytic system [33].

We should note that $\mathrm{Al}$ loadings dramatically increased the catalytic activity of butane isomerization as shown in Fig. 2. For example, the activity for the catalyst 9S/MP- $\mathrm{ZrO}_{2}$, without any $\mathrm{Al}$, is at a much lower level. Previously, Yang et al. [28] reported butane isomerization on mesoporous sulfated zirconia (without promoter) with a much lower level of activity. Our optimized Alloaded catalytic system in general increased the butane conversion by at least 6 times (see Fig. 2). In comparison, Kim et al. [34] reported only a 30\% increase in activity upon $\mathrm{Al}$ loading on SZ catalyst. They proposed Al-promoted SZ and SZ have identical acid sites. Al only helped in increasing residence time of the intermediates on surface of the catalyst.

However, we found the Al loading in our catalytic SZ materials changed much the nature of acid sites as shown in our XPS studies on the pyridine probes on the acid surfaces. We have identified three different acid sites (two Brønsted acid sites and one Lewis acid site) by XPS study of the adsorbed pyridine on Al-promoted SZ catalysts. They may be involved differently in the catalytic action. For considering their roles in the catalytic isomerization of alkane, we need to consider its molecular mechanism. The overall reaction mechanism of the isomerization of $n$-butane over sulfated zirconia is summarized in Scheme 1. Both monomolecular [35] and bimolecular mechanism [36] are included. In monomolecular mechanism, as shown in the left-hand side of Scheme 1, $n$-butane is first activated by a dehydrogenation process to form butene which is converted to secondary butyl cation on the Brønsted acid sites. It subsequently isomerizes into the branched carbenium ion via the protonated cyclopropane intermediate. At the final step, isobutane is desorbed from the surface after accepting hydride from hydrogen adsorbed on active site or from substrate.

Table 1

Physico-chemical properties of sulfated zirconia supported on MCM-41, nanoparticles, and mesoporous material catalysts calcined above $650{ }^{\circ} \mathrm{C}$ with optimal alumina loading and alumina-free samples

\begin{tabular}{llllll}
\hline Catalyst & $\begin{array}{l}\text { Surface area } \\
\left(\mathrm{m}^{2} / \mathrm{g}\right)\end{array}$ & $\begin{array}{l}\text { Pore volume } \\
\left(\mathrm{cm}^{3} / \mathrm{g}\right)\end{array}$ & $\begin{array}{l}\text { Pore diameter } \\
(\AA)\end{array}$ & $\begin{array}{l}\text { Aluminum } \\
\text { content }(\mathrm{wt} \%)\end{array}$ \\
\hline 50SZ/MCM-41 & 482.91 & 0.36 & 21.95 & - & $\begin{array}{l}\text { Sulfur } \\
\text { content }(\mathrm{wt} \%)\end{array}$ \\
5A50SZ/MCM-41 & 451.27 & 0.36 & 21.41 & 0.61 & 1.03 \\
9S/MP-ZrO 2 & 107.31 & 0.12 & 40.41 & - & 1.60 \\
3AS/MP-ZrO & 164.09 & 0.14 & 31.81 & - & 1.45 \\
SZ-NP & 109.21 & 0.23 & 46.78 & 1.83 \\
2ASZ-NP & 145.32 & 0.28 & 47.05 & 1.48 & 0.89 \\
\hline
\end{tabular}




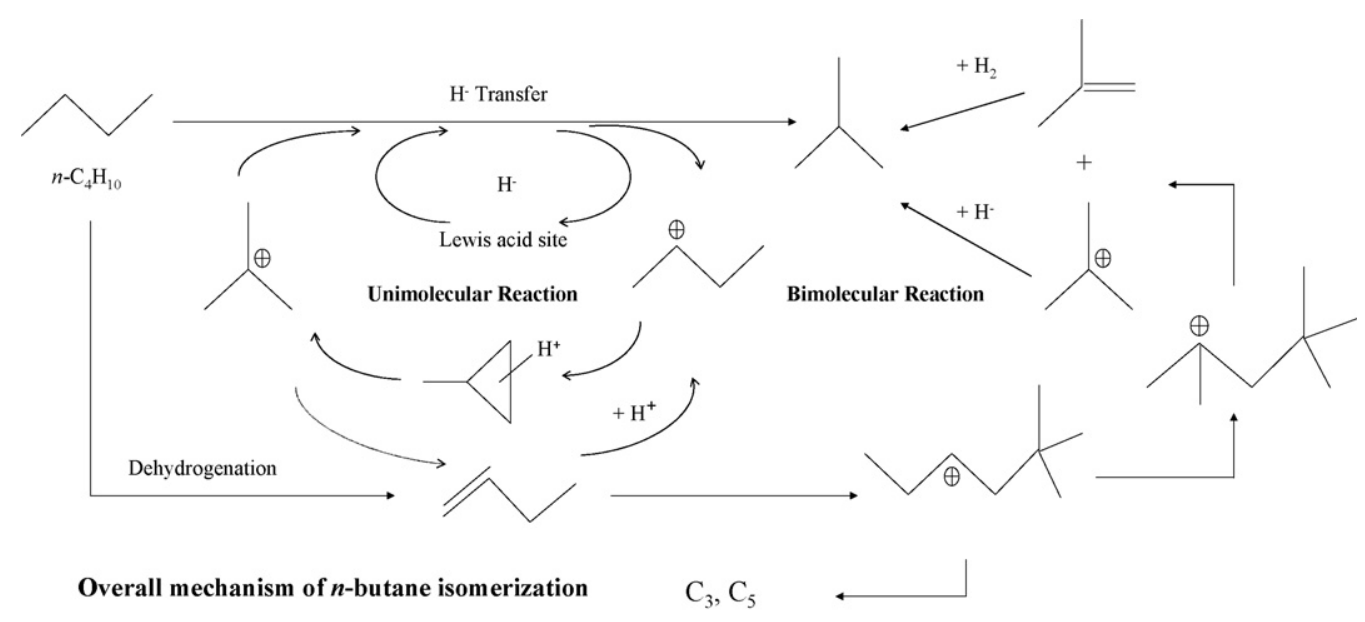

Scheme 1.

Furthermore, the tertiary carbenium ion would also be the intermediate in the bimolecular reaction since the $\mathrm{C}_{8}$ intermediate for bimolecular reaction is formed from reaction between $\mathrm{C}_{4}$ alkene and $\mathrm{C}_{4}$ cation. After the intermolecular reaction of surface alkene with carbenium ion, isomerization and disproportionate scission via $\mathrm{C}_{8}$ intermediates should proceed. Symmetric scission leads to isobutene and iso- $\mathrm{C}_{4}{ }^{+}$ asymmetric scission produces $\mathrm{C}_{3}$ and $\mathrm{C}_{5}$ hydrocarbons. Further condensations could lead to tri-molecular species which would be difficult to desorb and leads to coke formation.

As is described above, product distribution is related to the reaction path taken; for example, propane and pentanes are formed from cracking of $\mathrm{C}_{8}$ species when the reaction proceeds by the bimolecular mechanism. The reaction mechanism may thus be inferred from product distributions and its correlation with the nature of active sites in butane transformation. From the acid site distribution and product compositions, one can deduce which reaction path is predominant in each activity variation of catalyst. To illustrate this correlation, the catalysts $3 \mathrm{AS} / \mathrm{MP}-\mathrm{ZrO}_{2}, 4 \mathrm{AS} / \mathrm{MP}-\mathrm{ZrO}_{2}, 9 \mathrm{~S} / \mathrm{MP}-\mathrm{ZrO}_{2}$, and $\mathrm{MP}-\mathrm{ZrO}_{2}$ are chosen to be discussed as examples (Table 2).

In general, both unimolecular and bimolecular routes are possible. Observed variation in the selectivity could be related to different reaction paths. A high selectivity for isobutane would imply the isomerization may be predominantly through the unimolecular mechanism; while a low selectivity significant in a bimolecular mechanism. Therefore, it is proposed that the bimolecular reaction is preferred in the initial period which correlates with the formation of side products $\mathrm{C}_{3}$ and $\mathrm{C}_{5}$ and leads to coke and subsequently decreases the conversion. After $60 \mathrm{~min}$, the activity stabilized gradually and selectivity maintained a stable value above $90 \%$. The high selectivity and retarded decay suggested that the unimolecular mechanism is dominant in longer time-on-stream.

Based on the investigation of Py-XPS, the weak Brønsted acid sites are superior in amount to strong Brønsted and Lewis acid sites on the $3 \mathrm{AS} / \mathrm{MP}-\mathrm{ZrO}_{2}$ catalyst. From above, it thus seems reasonable to propose that the bimolecular mechanism over either strong or weak Brønsted acid sites is the predominant pathway in the initial period. Afterwards, it changes to the unimolecular pathway over the weak Brønsted acid sites. Then further evidence is presented on the catalytic behavior of $4 \mathrm{AS} / \mathrm{MP}-\mathrm{ZrO}_{2}$ catalyst. The profiles display a rapid decay of conversion and a bigger increase of selectivity in the initial 60 min. Comparing with $3 \mathrm{AS} / \mathrm{MP}-\mathrm{ZrO}_{2}$, this catalyst exhibits more strong Brønsted acid sites and less weak Brønsted acids on the surface. One can conclude that the strong Brønsted acid sites leads to high but rapidly decaying activity while it is

Table 2

The catalytic conversion, selectivity, and yield after 3 min reaction and at steady regime over MP-ZrO, $9 \mathrm{~S} / \mathrm{MP}-\mathrm{ZrO}{ }_{2}$, and $x \mathrm{AS} / \mathrm{MP}-\mathrm{ZrO}{ }_{2}(x=1-5$ mol$\%)$ catalysts

\begin{tabular}{|c|c|c|c|c|c|c|c|}
\hline \multirow[t]{2}{*}{ Catalyst } & \multirow[t]{2}{*}{ Conversion $(\%)$} & \multirow[t]{2}{*}{ Selectivity (\%) } & \multicolumn{5}{|c|}{ Yield (\%) } \\
\hline & & & $\mathrm{C}_{1}$ & $\mathrm{C}_{2}$ & $\mathrm{C}_{3}$ & $i-\mathrm{C}_{4}$ & $i-\mathrm{C}_{5}$ \\
\hline \multicolumn{8}{|l|}{ After 3 min } \\
\hline $\mathrm{MP}-\mathrm{ZrO}_{2}$ & 6.35 & 94.2 & 0.01 & 0.04 & 0.21 & 5.98 & 0.11 \\
\hline 9S/MP-ZrO ${ }_{2}$ & 11.72 & 87.2 & 0.04 & 0.09 & 0.84 & 10.22 & 0.53 \\
\hline $3 \mathrm{AS} / \mathrm{MP}-\mathrm{ZrO}_{2}$ & 54.24 & 88.7 & 0.3 & 0.98 & 4.84 & 48.11 & 0.01 \\
\hline $4 \mathrm{AS} / \mathrm{MP}-\mathrm{ZrO}_{2}$ & 52.33 & 84.9 & 1.51 & 1.86 & 4.89 & 43.57 & 0.50 \\
\hline \multicolumn{8}{|l|}{ After $60 \mathrm{~min}$} \\
\hline $\mathrm{MP}-\mathrm{ZrO}_{2}$ & 3.26 & 94.5 & 0.01 & 0.03 & 0.07 & 3.08 & 0.07 \\
\hline 9S/MP-ZrO $\mathrm{rO}_{2}$ & 5.64 & 89.2 & 0.01 & 0.03 & 0.18 & 5.03 & 0.39 \\
\hline $3 \mathrm{AS} / \mathrm{MP}-\mathrm{ZrO}_{2}$ & 47.57 & 90.0 & 0.17 & 0.61 & 2.13 & 42.58 & 2.08 \\
\hline $4 \mathrm{AS} / \mathrm{MP}-\mathrm{ZrO}_{2}$ & 28.13 & 93.2 & 0.07 & 0.25 & 0.80 & 26.23 & 0.78 \\
\hline
\end{tabular}

Reaction condition: reaction temperature $=250{ }^{\circ} \mathrm{C}, n$-butane $/ \mathrm{H}_{2}=1 / 10$ and WHSV $=0.62 \mathrm{~h}^{-1}$. 
the weak Brønsted acid sites gives a more stable activity. Furthermore, one notices that there is a big difference in the $\mathrm{C}_{3} /$ $i$ - $\mathrm{C}_{5}$ product ratio of $3 \mathrm{AS} / \mathrm{MP}-\mathrm{ZrO}_{2}$ between initial with steady state in Table 2. In general, if these $\mathrm{C}_{3} / i-\mathrm{C}_{5}$ products were formed via the unsymmetrical cracking of $\mathrm{C}_{8}$ intermediate in bimolecular pathway and the ratio should be close to one. However, the products ratio is 4.84/0.01 at the initial 3 min then changes to $2.13 / 2.08$ after $60 \mathrm{~min}$. According to this change in distribution, it is reasonable to propose that the more complex tri-molecular pathway would be undergoing in the initial phase of the reaction. In the tri-molecular route, the $\mathrm{C}_{12}$ intermediate may split into $C_{3}$ and $C_{9}$ fragments and increase the $C_{3}$ concentration. On the other hand, the more weighty $\mathrm{C}_{9}$ fragment could not be desorbed quickly and they may be further cracked to form more $\mathrm{C}_{2}$ and $\mathrm{C}_{3}$ products. Or they could be deposited as the coke on strong Brønsted acid sites and decreased the activity of catalyst. This behavior was also observed in the case of $4 \mathrm{AS} / \mathrm{MP}-\mathrm{ZrO}_{2}$ catalyst.

If the above inference is correct, one would expect that the catalyst with the highest ratio of weak Brønsted to strong Brønsted acid sites would produce the most stable catalytic behavior with the least cracking and coking. This is indeed the case for ASZ-NP. Table 3 gives the catalytic conversion and selectivity data of nanoparticle catalysts. Again Al promotion produces roughly a six-fold increase in conversion. All $\mathrm{C}_{3} / \mathrm{C}_{5}$ ratios for ASZ-NP at initial time have values (maybe with the except for 1ASZ-NP catalyst) close to one. They all possess pretty stable catalytic activity for longer time-on-stream. In Fig. 2, the most stable one 2ASZ-NP is shown as an example. This catalyst displays no obvious decay in $i$-C4 conversion and the $\mathrm{C}_{3} / \mathrm{C}_{5}$ ratio remains close to one all the time. We notice that this catalyst also exhibits the highest ratio of $\mathrm{SB}$ to $(\mathrm{WB}+\mathrm{L})$. These results support several conclusions: first, the multimolecular mechanism is the major pathway especially over the strong Brønsted acid sites in the initial period; and the second one is the weak Brønsted acid sites play an important role of maintaining the steady conversion.

The relative contribution of cracking and isomerization seem to depend on the concentration of the olefinic species on surface, which will depend on both the adsorption and desorption rate of the alkane. This means that the pressure of butane and the transport away from surface will affect the activity of isomerization. Previously, Chao et al. [37] had shown that for Pt-promoted SZ catalyst butane conversion would decrease with decreasing pressure but the cracking products would also decrease. In this work, we have shown that on the other hand, the nanoparticulate form of SZ, giving a better transport of products, would also help the selectivity towards isomerization.

The role of Lewis acid sites in the reaction may be considered by examining the catalytic behavior of un-promoted SZ catalysts which exhibit mainly Lewis acid sites (Fig. 3). The profiles of catalysts demonstrate the activity of Lewis acid sites is much less in the $n$-butane isomerization compared to Brønsted acid sites. However, Song and Kydd [38] proposed that Lewis acid may have some synergetic effect on the nearby Brønsted bisulfate acid sites by an induction effect of withdrawing electron from the nearby Brønsted acid [39]. It seems a minor amount of Lewis acid sites, although not contributing directly in the protonation steps, may help the activation of the catalyst. The role of Lewis acid, though minor, needs further investigation.

Finally, we would like to comment on the regeneration of the catalyst. For a SZ catalyst to be active, the retention of the sulfur and the active acid sites are necessary. While sulfur is necessary for acid sites, the retention of sulfur is not the sufficient condition for steady reaction. One needs also to activate the active sites [40]. From the results in Fig. 7, the catalytic activity can be restored simply by oxidation under air [41]. There is no need of re-sulfation in our catalyst. There has been report that the active sulfur species on the surface of SZ are quite labile and thus prone to loose in flow condition [42]. The presence of $\mathrm{Al}$ on the surface of our ASZ catalysts may have helped the retention of sulfur leading to a more stable catalyst for alkane isomerization. The deactivation of some of our ASZ catalyst may be attributed to the coke formation on strong acid sites. In this case, the activity can be regenerated by simple calcinations in the air.

Table 3

The catalytic conversion, selectivity, and yield after 3 min reaction and at steady regime over Z-NP, SZ-NP, and $x$ ASZ-NP $(x=1-2$ mol\%) catalysts

\begin{tabular}{|c|c|c|c|c|c|c|c|}
\hline \multirow[t]{2}{*}{ Catalyst } & \multirow[t]{2}{*}{ Conversion $(\%)$} & \multirow[t]{2}{*}{ Selectivity (\%) } & \multicolumn{5}{|c|}{ Yield $(\%)$} \\
\hline & & & $\mathrm{C}_{1}$ & $\mathrm{C}_{2}$ & $\mathrm{C}_{3}$ & $i-\mathrm{C}_{4}$ & $i-\mathrm{C}_{5}$ \\
\hline \multicolumn{8}{|l|}{ After $3 \mathrm{~min}$} \\
\hline Z-NP & 0.14 & 94.25 & - & - & - & 0.13 & - \\
\hline SZ-NP & 8.92 & 84.75 & 0.01 & 0.06 & 0.72 & 7.56 & 0.57 \\
\hline 1ASZ-NP & 53.15 & 81.39 & 0.31 & 0.93 & 5.63 & 43.26 & 3.01 \\
\hline 1.5ASZ-NP & 51.53 & 90.19 & 0.13 & 0.42 & 2.32 & 46.48 & 2.18 \\
\hline 2ASZ-NP & 49.57 & 87.55 & 0.19 & 0.62 & 3.01 & 43.47 & 2.36 \\
\hline \multicolumn{8}{|l|}{ After $60 \mathrm{~min}$} \\
\hline Z-NP & 0.14 & 94.12 & - & - & - & 0.13 & - \\
\hline SZ-NP & 6.54 & 89.76 & 0.01 & 0.03 & 0.34 & 5.87 & 0.29 \\
\hline 1ASZ-NP & 41.21 & 89.52 & 0.17 & 0.62 & 1.94 & 36.89 & 1.57 \\
\hline 1.5ASZ-NP & 46.61 & 89.45 & 0.15 & 0.51 & 2.24 & 41.69 & 2.01 \\
\hline 2ASZ-NP & 46.83 & 92.59 & 0.13 & 0.46 & 1.51 & 43.36 & 1.37 \\
\hline
\end{tabular}

Reaction condition: reaction temperature $=250{ }^{\circ} \mathrm{C}, n$-butane $/ \mathrm{H}_{2}=1 / 10$ and WHSV $=0.62 \mathrm{~h}^{-1}$. 
We should also note that the activation process of dehydrogenation of butane to butene is not discussed in this paper. Recent works by Li et al. [43] have shown that the surface $\mathrm{SO}_{3}$ species are also important in the oxidative de-hydrogenation step to initiate the catalytic cycle (Scheme 1). It needs a delicate balance of the initiation and isomerization steps in order to produce a steady and active sulfated zirconia catalyst.

In this work, the use of XPS investigation of adsorbed pyridine has allowed us to differentiate the three different surface acid sites of the catalysts. We are able then to correlate the catalytic activity of ASZ with weak Brønsted acid sites through variation of the loading of alumina. This is rather satisfying because previous quantitative determination of Brønsted acid in SZA, based on H/D exchange method, cannot differentiate between the strong and weak Brønsted acids [44]. Consequently it was asserted that the catalytic activity was not well correlated with the total number of Brønsted acid sites [45]. We have been able to better differentiate acid types and established the correlation between activity behavior and distribution of acid types.

The promoting and stabilizing effect of $\mathrm{Al}$ on sulfated zirconia in butane isomerization without the use of expensive $\mathrm{Pt}$ is technologically encouraging. We may thus be able to develop a new generation of catalyst for alkane isomerization. In fact, recently we have found Al-promoted SZ catalysts catalyze excellently and very stably the isomerization of pentane [46] and hexane [47] as well. Further studies to understand the detailed reasons for the excellent catalytic behavior in Alpromoted sulfated zirconia for the isomerization of pentane and hexane are desirable.

\section{Conclusion}

Promotion of sulfated zirconia with alumina improved the efficiency and stability of sulfated zirconia catalysts in $n$-butane isomerization, with a substantial effect when alumina and sulfation was introduced via impregnation. The increase of activity was determined primarily by the amount of alumina addition and then the temperature of calcination. First, mesoporous carriers can help better the dispersion of sulfated tetragonal $\mathrm{ZrO}_{2}$. Second, the addition of $\mathrm{Al}$ can prevent the transformation of tetragonal sulfated zirconia into monoclinic sulfated zirconia. Third, according to the results of catalytic activities and characterization of acid sites, the remarkable activity and stability of the Al-promoted catalysts are due to an optimized distribution of acid sites strength. For the three catalysts considered, ASZ-MCM-41, ASZ-NP and AS/MP$\mathrm{ZrO}_{2}$, we have correlated maximum catalytic activity with a corresponding optimum distribution of acid sites. Al loading results in an enhanced amount of weak Brønsted acid sites with intermediate strength which is important for the maintenance of a steady catalytic cycle in the isomerization of butane.

The overall reaction mechanism of the isomerization of $n$ butane over sulfated zirconia was considered so that product distribution is related to the reaction pathway. We demonstrated two conclusions: firstly, in the initial period the bimolecular mechanism is the major pathway over the strong Brønsted acid sites. The initial decay in activity results from coking on the strong Brønsted acid sites and obstruction of mesoporous channels. Secondly, the weak Brønsted acid sites play an important role to maintain the steady conversion in the subsequent period. Besides, the excellent activity with slight decay of nanoparticle catalyst (ASZ-NP) suggested its more open pore system can avoid better the obstruction of mesopores.

\section{Acknowledgments}

This work was supported by a grant from the National Science Council of Taiwan through the Academy Excellent program (NSC-94 -2752- M- 002-004-PAE). Prof. C.C. Chang and Mr. S.C. Tsai are acknowledged for kind helps in the XPS measurements.

\section{References}

[1] X.M. Song, A. Sayari, Catal. Rev. 38 (1996) 329.

[2] B.H. Davis, R.A. Keogh, R. Srinivasan, Catal. Today 20 (1994) 219.

[3] A. Corma, Chem. Rev. 95 (1995) 559.

[4] Z. Hong, K.B. Fogash, J.A. Dumesic, Catal. Today 51 (1999) 269.

[5] Z. Gao, J.M. Chen, W.M. Hua, Y. Tang, Stud. Surf. Sci. Catal. 90 (1994) 507.

[6] C. Morterra, G. Cerrato, F. Pinna, M. Signoretto, G. Strukul, J. Catal. 149 (1994) 181.

[7] F.T.T. Ng, N. Hovat, Appl. Catal. A 123 (1995) L197.

[8] H. Liu, V. Adeeva, G.D. Lei, W.M.H. Sachtler, J. Mol. Catal A: Chem. 100 (1995) 35.

[9] H. Liu, G.D. Lei, W.M.H. Sachtler, Appl. Catal. A 146 (1996) 165.

[10] C.X. Miao, W.M. Hua, Z. Gao, Chin. J. Catal. 18 (1997) 13.

[11] C.Y. Hsu, C.R. Heimbuch, C.T. Armes, B.C. Gates, J. Chem. Soc. Chem. Comm. 22 (1992) 1645.

[12] M.A. Coelho, D.E. Resasco, E.C. Skabwe, R.L. White, Catal. Lett. 32 (1995) 256.

[13] Z. Gao, Y.D. Xia, W.M. Hua, C.X. Miao, Top. Catal. 6 (1998) 101.

[14] R. Olindo, F. Pinna, G. Strukul, P. Canton, P. Riello, G. Cerrato, G. Meligrana, C. Morterra, Stud. Surf. Sci. Catal. 130 (2000) 2375.

[15] J.A. Moreno, G. Poncelet, J. Catal. 203 (2001) 453.

[16] J.H. Wang, C.Y. Mou, Appl. Catal. A 286 (2005) 128.

[17] K. Arata, H. Matsuhashi, M. Hino, H. Nakamura, Catal. Today 81 (2003) 17.

[18] G.K. Chuah, S. Jaenicke, B.K. Pong, J. Catal. 175 (1998) 80.

[19] C.L. Chen, T. Li, S.F. Cheng, H.P. Lin, C.J. Bhongale, C.Y. Mou, Micro. Mesop. Mater. 50 (2001) 201.

[20] C.L. Chen, T. Li, H.P. Lin, C.Y. Mou, Appl. Catal. A: Gen. 215 (2001) 21.

[21] Q.H. Xia, K. Hidajat, S. Kawi, Chem. Comm. (2000) 2229.

[22] H.K. Mishra, A.K. Dalai, D.D. Das, K.M. Parida, N.C. Pradhan, J. Colloid Interface Sci. 272 (2004) 378.

[23] U. Ciesla, M. Fröba, G. Stucky, F. Schüth, Chem. Mater. 11 (1999) 227.

[24] Y. Sun, L. Yuan, S. Ma, Y. Han, L. Zhao, W. Wang, C.L. Chen, F.S. Xiao, Appl. Catal. A 268 (2004) 17.

[25] T. Lei, W.-M. Hua, Y. Tang, Y.-H. Yue, Z. Gao, Chem. J. Chin. Univ. 21 (2000) 1240.

[26] Y.Y. Huang, T.J. McCarthy, W.M.H. Sachtler, Appl. Catal. A 148 (1996) 135.

[27] U. Ciesla, S. Schacht, G.D. Stucky, K.K. Unger, F. Schuth, Angew. Chem. Int. Ed. Engl. 35 (1996) 541.

[28] X. Yang, F.C. Jentoft, R.E. Jentoft, F. Girgsdies, T. Ressler, Catal. Lett. 81 (2002) 25.

[29] C. Defosse, P. Canesson, J. Chem. Soc. Faraday Trans. 1 (1976) 2565.

[30] J.A. Wang, M.A. Valenzuela, J. Salmones, Catal. Today 68 (2001) 21.

[31] B.H. Li, R.D. Gonzalez, Appl. Catal. 174 (1998) 109.

[32] C.L. Chen, T. Li, S. Cheng, N. Xu, C.Y. Mou, Catal. Lett. 78 (2002) 223. 
[33] S.Y. Chen, L.Y. Jang, S. Cheng, J. Phys. Chem. B 110 (2006) 11761.

[34] S.Y. Kim, N. Lohitharn, J.G. Goodwin Jr., R. Olindo, F. Pinna, P. Canton, Catal. Commun. 7 (2006) 209.

[35] X. Li, K. Nagaoka, L.J. Simon, R. Olindo, J.A. Lercher, J. Catal. 232 (2005) 456.

[36] S.Y. Kim, N. Lohitharn, J.G. Goodwin Jr., D. Farcasiu, Appl. Catal. 207 (2006) 281

[37] K.J. Chao, H.C. Wu, L.J. Leu, J. Catal. 157 (1995) 289.

[38] S.X. Song, R.A. Kydd, J. Chem. Soc., Faraday Trans. 94 (1998) 1333.

[39] A. Clearfield, G.D.P. Serrette, A.H. Khazi-Syed, Catal. Today 20 (1994) 295.

[40] X. Li, K. Nagaoka, L.J. Simon, J.A. Lercher, C. Breitkopf, S. Matysik, H. Papp, J. Catal. 230 (2005) 214.
[41] K. Föttinger, E. Halwax, H. Vinek, Appl. Catal. A 301 (2006) 115.

[42] X. Li, K. Nagaoka, R. Olindo, J.A. Lercher, J. Catal. 238 (2006) 39.

[43] X. Li, K. Nagaoka, L.J. Simon, R. Olindo, J.A. Lercher, A. Hofmann, J. Sauer, J. Am. Chem. Soc. 127 (2005) 16159.

[44] R. Olindo, A. Goeppert, D. Habermacher, J. Sommer, F. Pinna, J. Catal. 197 (2001) 344.

[45] Y. Sun, S. Walspurger, B. Louis, J. Sommer, Appl. Catal. A 292 (2005) 200.

[46] W. Wang, J.H. Wang, C.L. Chen, N.P. Xu, C.Y. Mou, Catal. Today 97 (2004) 307.

[47] C.J. Cao, S. Han, C.L. Chen, N.P. Xu, C.Y. Mou, Catal. Commun. 4 (2003) 511. 